A. Sellas; F.J. Rodriguez; A. Bermúdez; M.Romero; M. Riesco; J.C Cobeta; F.Medina; A. Aragón; ML. García; A. Urruticoechea; CM. González; E. Judez; B. González; P. Fernández; L. Pantoja; R. Morlá.

This study was funded by Pfizer.

Disclosure of Interest: None declared

DOI: 10.1136/annrheumdis-2017-eular.3780

\section{SAT0475 RECENT ONSET PSORIATIC ARTHRITIS: BASELINE DATA FROM THE REAPSER STUDY}

R. Queiro, A. Laiz Alonso, H.S. Park, C. Montilla Morales, E. Galíndez Agirregoikoa, J.J. Bethencourt Baute, S. Bustabad Reyes, P. Tejón Menéndez, M.Á. Belmonte, J.A. Pinto Tasende, E.A. Blanco Morales, J. Ramír.

Rheumatology, Hospital Universitario Central de Asturias (Coordinating Center), Oviedo, Spain

Background: The natural history of psoriatic arthritis (PsA) is very little known and the information regarding prospective cohorts is very scarce worldwide, including our country. REAPSER (Spanish Rheumatology Society Registry of Psoriatic Arthritis) is the first registry of Spanish patients with recent onset PSA.

Objectives: To describe the baseline characteristics of patients included in the REAPSER cohort.

Methods: Observational, multicentric study (34 centers), with consecutive inclusion. We included adults of both sexes 18 years of age or older with PsA that met CASPAR criteria, and duration of less than two years since the appearance of symptoms attributed to PsA. Annual follow-up visits will be carried out for 5 years. Measurements: socio-demographic data; employment status and impact of the disease; family history of PsA and other inflammatory diseases; comorbidities and treatment; lifestyle; use of health services; clinical status at the time of diagnosis of PsA; anthropometric data; clinical evaluation of PsA manifestations; radiographic evaluation; analytical determinations; treatment of PsA. The study has been approved by the ethical committees of the participating centers.

Results: Two hundred and fifteen consecutive patients were included, mean age $49.8 \pm 13.9$ years.

Baseline characteristics of the cohort

\begin{tabular}{|c|c|}
\hline Parameter & $\mathrm{N}: 215$ \\
\hline Men & $67.4 \%$ \\
\hline Women & $32.6 \%$ \\
\hline Active worker & $59.5 \%$ \\
\hline Unemployed & $12.1 \%$ \\
\hline Retired/pensioner & $17.7 \%$ \\
\hline Job change last year & $4.7 \%$ \\
\hline University studies & $20 \%$ \\
\hline Smoking & $30.2 \%$ \\
\hline BMI & $27.7 \pm 5.2$ \\
\hline Weekly alcohol consumption & 0 SDU $(0-4)$ \\
\hline Family history of psoriasis & $41.4 \%$ \\
\hline Family history of PsA & $9.3 \%$ \\
\hline Family history of other arthritis & $6.5 \%$ \\
\hline Charlson's Comorbidity Index & $0: 46.5 \% .1-2: 35.3 \% .3-4: 14.4 \% .>4: 3.8 \%$ \\
\hline Psoriasis at baseline & $88 \%$ \\
\hline PASI & $1.5(0.6-4.3)$ \\
\hline Joint pattern & Peripheral: $81.5 \%$. Axial: $5.2 \%$. Mixed: $13.3 \%$ \\
\hline TJC68 & $4(2-8)$ \\
\hline SJC66 & $2(1-4)$ \\
\hline BASDAI & $3.9(3-4.4)$ \\
\hline Dactylitis & $41.9 \%$ \\
\hline Enthesitis & $25 \%$ \\
\hline Uveitis & $0.5 \%$ \\
\hline Pain & $5(3-7)$ \\
\hline Patient's global disease activity & $5(3-7)$ \\
\hline PsAID & $3.8(1.8-6)$ \\
\hline Steinbrocker Index (0-168) & $0(0-4)$ \\
\hline Cardiovascular events & $5.7 \%$ \\
\hline HLA-B27 & $12.3 \%$ \\
\hline ESR & $13(6-25)$ \\
\hline NSAIDs & $75 \%$ \\
\hline GC & $28.3 \%$ \\
\hline Synthetic DMARDs & $53.2 \%$ \\
\hline Biological DMARDS & $1.5 \%$ \\
\hline
\end{tabular}

Values are expressed as percentages, means with standard deviation and medians with their IQR (interquartile range). SDU: Standard Drink Units. PsAID: Psoriatic Arthritis Impact of Disease.

Conclusions: The baseline situation of Spanish patients with newly diagnosed PsA corresponds to that of a disease with slight cutaneous involvement and predominance of oligoarticular arthritis. Unsurprisingly, structural damage is scarce but not zero. The impact of the disease is still low in these early stages, however $18 \%$ of patients have a high Charlson's comorbidity index $(>3)$ and almost $5 \%$ of patients have had to change their employment status in the last year due to its PsA.

Disclosure of Interest: None declared

DOI: 10.1136/annrheumdis-2017-eular.4268

\section{SAT0476 DEMOGRAPHIC, CLINICAL, AND LABORATORY CHARACTERISTICS OF ELDERLY ONSET PSORIATIC ARTHRITIS}

S. Kobak ${ }^{1}$, M. Orman ${ }^{2}{ }^{1}{ }^{1}$ Rheumatology, Istinye University Faculty of Medicine, LIV Hospital, Istanbul; ${ }^{2}$ Statistics, Ege University Faculty of Medicine, Izmir, Turkey

Background: Psoriatic arthritis (PsA) is a chronic inflamatory disease characterized with axial and peripheral joints involvement. It is rarely affects patients older than 65 years old.

Objectives: The purpose of this study is to compare and evaluate the demographic, clinical and laboratory features of elderly-onset psoriatic arthritis (EOPsA) and young-onset (YOPsA) patients.

Methods: One hundred and eighty patients diagnosed with PsA according to CASPAR criteria and followed-up in single center were included in this study. The patients with initial symptoms started after age 65 were accepted as EOPsA Demographic, clinical, and laboratory data and the medications which the patients recieved were recorded and retrospectively evaluated.

Results: Nineteen (10.5\%)of 180 patients were diagnosed as EOPsA, and 161 $(89.5 \%)$ patients were evaluated as YOPsA. Mean patient age was 42.1 years for YOPsA group and 68.3years for elderly onset group. Mean duration of disease was 5.6 years for early onset group and 1.3 years for elderly onset group $(\mathrm{p}=0.001)$. Fourteen $(73.3 \%)$ of 19 EOPsA patients were female and 5 of them were male. Higher rates of fatique, pain scores, comorbid diseases and acute phase reactants were detected in EOPsA patients comparing to YOPsA $(p=0.000, p=0.000, p=0.001$ and $p=0.001$ respectively). YOPsA patients have more dactilitis, nail involvement, elevated PASI scores, and smoking habitus when compared with EOPsA patients ( $p=0.019, p=0.03, p=0.005, p=0.004$ respectively). In terms of the treatment options chosen, there was no significant difference in the use of non-steroidal anti-inflammatory drugs (NSAIDs), corticosteroids (CS), methotrexate (MTX), and sulfasalazine (SSL), but there was a more frequent use of anti-tumor necrosis factor -alpha in YOPsA group.

Conclusions: Herein we showed that YOPsA and EOPsA patients may have different demographic, clinical, and laboratory features. EOPsA patients are characterized with higher rates of fatique, pain scores, comorbid diseases, and acute phase reactants and less dactilitis, nail involvement and anti-TNF-alpha usage.

Disclosure of Interest: None declared

DOI: 10.1136/annrheumdis-2017-eular.1378

\section{SAT0477 THE COMPARISON OF ULTRASOUND SYNOVITIS AND ENTHESITIS FINDINGS AND CLINICAL FINDINGS IN PATIENTS WITH PSORIATIC ARTHRITIS AND SKIN PSORIASIS}

T. Okano ${ }^{1}$, K. Inui ${ }^{1}$, Y. Sugioka ${ }^{2}$, K. Mamoto ${ }^{1}$, H. Yoshimura ${ }^{1}$, T. Koike ${ }^{2,3}$ H. Nakamura ${ }^{1} .{ }^{1}$ Department of Orhopedic surgery; ${ }^{2}$ Center for Senile Degenerative Disorders (CSDD), Osaka City University Graduate School of Medicine, Osaka; ${ }^{3}$ Search Institute for Bone and Arthritis Disease (SINBAD), Shirahama Foundation for Health and Welfare, Wakayama, Japan

Background: Conventionally, the assessment of affected joint count in patients with psoriatic arthritis (PsA) was relied for the detection of swelling and tenderness in the joints and enthesis by clinical physical assessment. To date, the modern imaging tool such as ultrasound (US) can detect inflammation in the joint and enthesis more sensitively than clinical assessment.

Objectives: The aim of this study was to research the prevalence of US syovitis and enthesitis findings in patients with PsA and psoriasis ( $\mathrm{PsO}$ ) comparing with clinical assessment.

Methods: Total 100 patients, 54 patients with PsA and 46 patients with PsO, were consecutively included. HI VISION Ascendus (HitachiAloka Medical, Tokyo, Japan) was used with a 18-MHz linear array transducer. US examination was performed in MCP, PIP, DIP and wrist joints in both hand. Grayscale (GS) and power Doppler (PD) US were scored on a 0-3 semiquantitative scale for each joint. Moreover, the US assessment of enthesis was performed. Lateral epicondyle, triceps enthesis, the proximal and distal patella tendon enthesis, Achilles tendon and fascia plantaris tendon enthesis was scanned in both GS and PD assessment. Abnormal findings of enthesis was defined structure thickness, bursitis erosion, calcification and power Doppler signal.

Results: US synovitis was found in $81.5 \%(n=44)$ and $60.9 \%(n=28)$ by GS, $66.7 \%(n=36)$ and $45.7 \%(n=21)$ by PD assessment, respectively in patients with PsA and PsO. Active synovitis (GS grade $\geqq 2$ and/or PD grade $\geqq 1$ ) was found

\begin{tabular}{lccc}
\hline & PsA $(\mathrm{n}=54)$ & PsO $(\mathrm{n}=46)$ & P value \\
\hline Male (\%) & $26(48.1 \%)$ & $26(56.5 \%)$ & 0.429 \\
Age (years) & $55.4 \pm 15.0$ & $57.5 \pm 15.3$ & 0.508 \\
Height $(\mathrm{cm})$ & $161.6 \pm 9.8$ & $161.6 \pm 9.5$ & 0.969 \\
Weight $(\mathrm{kg})$ & $62.7 \pm 15.5$ & $63.1 \pm 13.9$ & 0.905 \\
BMI & $23.8 \pm 3.9$ & $24.0 \pm 3.6$ & 0.883 \\
Duration of psoriasis (years) & $15.6 \pm 13.6$ & $17.5 \pm 19.7$ & 0.584 \\
PASI & $11.7 \pm 13.4$ & $8.9 \pm 7.5$ & 0.432 \\
PASE & $45.8 \pm 14.6$ & $29.8 \pm 11.9$ & $<0.001$ \\
Active US synovitis (GS $\geq 2$, PD $\geq 1)$ & $37(68.5 \%)$ & $21(45.7 \%)$ & 0.026 \\
US enthesitis (any pathological findings) & $47(87.0 \%)$ & $26(56.5 \%)$ & $<0.001$ \\
\hline
\end{tabular}


$68.5 \%(n=37)$ in PsA and $45.7 \%(n=21)$ in PsO. US synovitis was more frequently found than clinical assessment. The most common sites of inflammatory synovitis were the wrist. US enthesopathy was found in $87.0 \%(n=47)$ in patients with PsA $56.5 \%(n=26)$ in patients with PsO. US enthesitis was also more frequently found than clinical assessment. The most common sites of enthesopathy were the enthesis in lateral epicondyle, quadriceps and Achilles tendon.

Conclusions: Our results showed that US was able to detect a high prevalence of inflammatory synovitis in peripheral joints and enthesis in patients with PsA. Moreover, subclinical inflammatory findings were also found in patients with PsO by US. US examination is useful to detect the inflammatory condition in patients with PsA and PsO than clinical examination.

Acknowledgements: We wish to thank Setsuko Takeda, Ayumi Hashimoto and Emi Yamashita for their special efforts as a sonographer and collecting data. Disclosure of Interest: None declared

DOI: 10.1136/annrheumdis-2017-eular.5028

\section{SAT0478 RAPID3 QUESTIONNAIRE HAS HIGH DISCRIMINATING ABILITY IN MINIMAL DISEASE ACTIVITY ATTAINMENT IN PATIENTS WITH EARLY PSORIATIC ARTHRITIS TREATED ACCORDING TO TIGHT CONTROL STRATEGY IN DAILY CLINICAL PRACTICE (RESULTS OF ONE-YEAR OPEN-LABEL REMARCA STUDY)}

T. Korotaeva, E. Loginova, A. Koltakova, L. Denisov, M. Chamurlieva, D. Karateev, E. Nasonov. V.A.Nasonova Research Institute of Rheumatology, Moscow, Russian Federation

Background: RAPID3 is an instrument based on patient's report outcomes (PROs) for the assessment of remission and disease activity in rheumatoid arthritis. The advantages of this questionnaire in treat-to-target (T2T) strategy in early psoriatic arthritis (EPSA) have not been studied properly.

Objectives: to study discriminating ability of RAPID3 in minimal disease activity (MDA) attainment in patients with EPsA treated during one year according to tight control strategy.

Methods: $61(\mathrm{M} / \mathrm{F}-29 / 32)$ patients (pts) with active EPsA, according to CASPAR criteria, mean age $37 \pm 10.6$ years, PsA duration $11.3 \pm 10.2$ months, psoriasis duration $75.4 \pm 80.9$ months were included. All pts signed a consent form for participation in the open-label REMARCA study. At baseline and after 1year (yr.) of therapy all pts underwent evaluation of PsA activity by Tender Joint count (TJC78), Swollen Joint Count (SJC76), physician's global disease activity (PhGA) VAS, DAS, CRP (mg/l) and by PROs - patient pain global assessment VAS, Patient global disease activity (PGA) VAS, Health Assessment Questionnaire (HAQ) and RAPID3. The dose of Methotrexate (MTX) subcutaneous (s/c) was escalated by $5 \mathrm{mg}$ every 2 weeks from $10 \mathrm{mg} / \mathrm{wk}$ up to $20-25 \mathrm{mg} / \mathrm{wk}$. If pts did not achieve MDA after 3-6 months of MTX mono-therapy, combination therapy (CoT) of MTX+Adalimumab (ADA) was started in a standard regime; CoT was continued up to $1 \mathrm{yr}$. The proportion of pts who achieved MDA was calculated. M $\pm \mathrm{SD}, \mathrm{Me}$ [Q25;Q75], \%, Spearman rank correlation R, W-test, U-test, ROC-curve analysis were performed. All $p<0.05$ were considered to indicate statistical significance.

Results: By 1 yr. of therapy 36 out of 61 pts (59\%) and 25 out of 61 pts (41\%) were treated with MTX and with MTX+ADA accordingly. Significant improvements in PsA activity and PROs from baseline up to $1 \mathrm{yr}$. were observed: DAS 3.93 [3.20-4.58]/1.36 [0.82-2.25], SJC 7 [5-11]/1 [0-3], TJC 8 [6-1]/1 [0-3], PhGA 56 [48-69]/10 [5-20] and VAS pain 54 [48-68]/11 [1-20], PGA 55 [49-68]/14 [7-24], HAQ $0.75[0.50-1] / 0[0-0.63]$ accordingly (for all W-test $p<0.001$ ). Significant positive correlations between RAPID3 and PsA activity, PROs and CRP are shown in table 1 (for all $R p<0.001$ ).

MDA was seen in 43 out of $61 \%$ pts $(70.5 \%)$. At the same time RAPID3 and CRP significantly decreased from 12.7 [9.2-16.8] to 4.3 [2.0-7.8] and from 16.6 [8.6-34.6] to $2.1[0.9-6.7] \mathrm{mg} / \mathrm{l}$ accordingly (for all W-test, $\mathrm{p}<0.001$ ). Among those who have achieved MDA RAPID3 was in "near remission" status and significantly

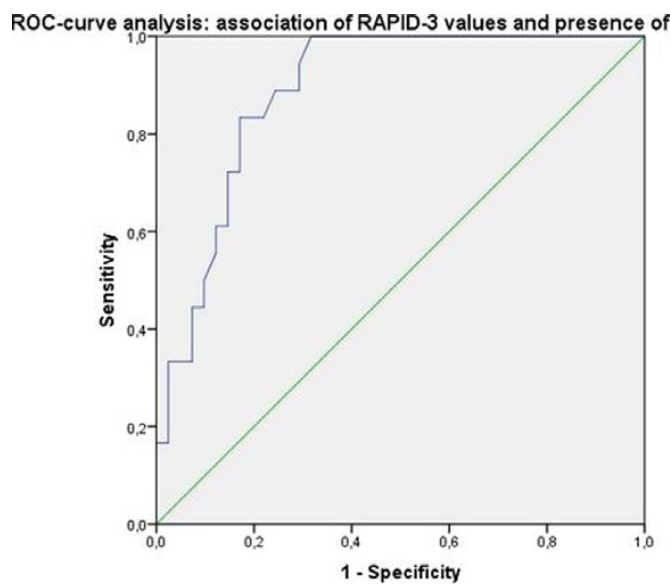

Diagonal segments are produced by ties

\begin{tabular}{lc}
\hline Parameters & $\mathrm{R}$ \\
\hline DAS & 0.74 \\
TJC78 & 0.68 \\
SJC76 & 0.63 \\
PGA VAS & 0.82 \\
Pain VAS & 0.83 \\
PtGA VAS & 0.81 \\
CRP & 0.69 \\
\hline
\end{tabular}

less compared to pts that did not achieve MDA-2.5 [1.3-5.3] and 8.1 [6.0-15.1] accordingly (U-test, $\mathrm{p}<0.001$ ). According to the results of ROC-curve analysis RAPID3 score had a high discriminating ability for the presence of MDA - AUC 0.888 [0.808-0.969] (Fig. 1).

Conclusions: RAPID3 based on PROs is a simple instrument for evaluating PsA activity. RAPID3 has shown high discriminating ability in MDA attainment in EPsA pts treated according to tight-control strategy, and could be useful in daily clinical practice.

Disclosure of Interest: None declared

DOI: 10.1136/annrheumdis-2017-eular.3010

\section{SAT0479 INCREASED CAROTID INTIMA-MEDIA THICKNESS CAN DISCRIMINATE SIGNIFICANT CORONARY ARTERY STENOSIS BY CORONARY CT ANGIOGRAM IN PATIENTS WITH PSORIATIC ARTHRITIS}

T.H. Cheng ${ }^{1}$, Q. Shang ${ }^{1}$, E.K.M. Li ${ }^{1}$, K.T. Wong ${ }^{2}$, A.P.W. Lee ${ }^{1}$, C.C. Szeto ${ }^{1}$, L.S. Tam ${ }^{1} .{ }^{1}$ Department of Medicine and Therapeutics, the Chinese University of Hong Kong; ${ }^{2}$ Department of Diagnostic and Interventional Radiology, The Prince of Wales Hospital, Hong Kong, Hong Kong

Background: PsA patients have increased morbidity \& mortality due to cardiovascular disease (CVD). However, their CV risk were underestimated by various $\mathrm{CV}$ risk score ${ }^{1}$. Subclinical carotid atherosclerosis may be considered as surrogate marker of coronary artery disease (CAD) in the general population ${ }^{2}$ while it remained uncertain for PsA patients

Objectives: To assess the relationship between carotid artery disease by ultrasound (US) and CAD by coronary computed tomography angiography (CCTA) and identify US parameters predictive of significant CAD

Methods: 91 subjects (56 males; age: $50 \pm 11$ years; disease duration $9.4 \pm 9.2$ years) without overt CVD who underwent CCTA \& carotid US (interval between two exams:2 [1-7] months) were recruited. Carotid intima-media thickness (cIMT)\& the presence of plaque were determined by high resolution US in the distal CCA, bulb \& proximal ICA bilaterally. Significant coronary artery stenosis was defined as stenosis of the lumen $>50 \%$

Results: Carotid plaque was present in $33(36 \%)$ patients \& coronary plaque was present in $55(60 \%)$ patients while $9(10 \%)$ patients had significant coronary artery stenosis. $36(40 \%)$ patients had non-zero calcium score (CAC+ group). The mean CIMT was significantly higher in $\mathrm{CAC}+$ group compared to $\mathrm{CAC}=0$ group $[0.70 \pm 0.11 \mathrm{~mm}$ vs $0.64 \pm 0.11 \mathrm{~mm}, p=0.031]$. There was a trend suggesting the mean CIMT increases with increasing CAC score, while the prevalence of carotid plaque increased significantly with rising calcium score (Table1). The mean cIMT increased significantly with number of coronary vessels habouring plaque, while there was a trend suggesting the max cIMT and the prevalence of carotid plaque may increase in patients with rising number of coronary vessels harboring plaques The mean \& max cIMT were significantly higher in SS+ group than SS- group [mean cIMT: $0.76 \pm 0.07 \mathrm{~mm}$ vs0.65 $\pm 0.12 \mathrm{~mm}, p=0.011 ; \max$ cIMT: $0.93 \pm 0.14 \mathrm{~mm}$ vs $0.80 \pm 0.16 \mathrm{~mm}, p=0.020$ ] (Table1). The prevalence of carotid plaque was similar between SS+ \& SS- group [29 (35.4\%) vs $4(44.4 \%), p=0.421]$. Using multivariate logistic regression, mean \& max cIMT were independent explanatory variable of significant coronary stenosis after adjusting age, gender, disease duration \& damaged joint count. The OR of significant coronary stenosis of every $0.01 \mathrm{~mm}$ increase in mean \& max cIMT were $1.07(95 \% \mathrm{Cl}: 1.00-1.15, p=0.042)$ and 1.06 $(95 \% \mathrm{Cl}: 1.00-1.11, p=0.036)$. Mean cIMT of $0.66 \mathrm{~mm}$ was the optimal cut off

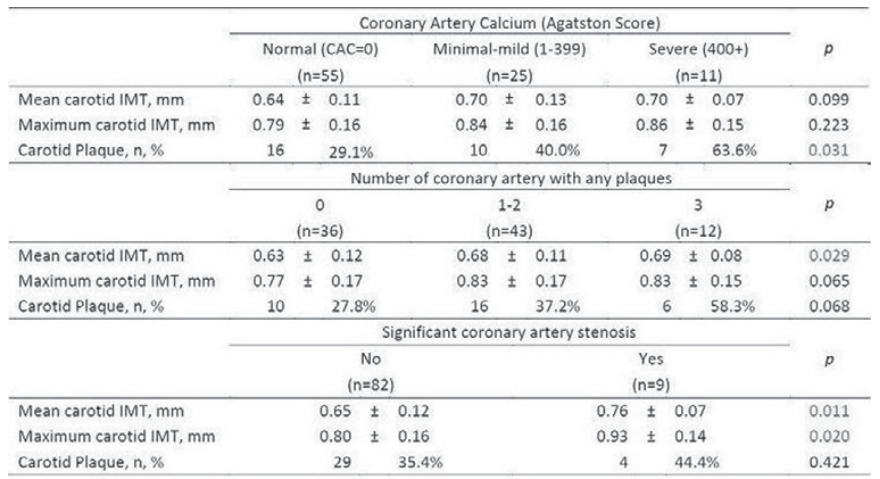

Table 1. Relationship between carotid artery disease by ultrasound and coronary artery disease by coronary computed tomography angiography. 